\title{
АЛГОРИТМ УТОЧНЕНОГО ПОЗИЦІОНУВАННЯ В НАВІГАЦЙНИХ СИСТЕМАХ ДОПОВНЕНОЇ РЕАЛЬНОСТІ
}

Анотація: Розвиток технологій доповненої реальності та можливостей і потужності мобільних пристроїв призвів до виникнення окремого класу мобільних навігаційних систем доповненої реальності, що мають значні додаткові можливості відображення інформації та іiї використання. Основною вимогою до таких систем є необхідність синхронізації позиції та маршруту користувача з об'єктами навколишнього середовища, що потребує високої точності позиціонування та орієнтації користувача у просторі. В статті проведений аналіз існуючих методів визначення позиції в просторі, та запропоновано алгоритм, що надає суттєвий приріс точності позиціонування в системах доповненої реальності.

Ключові слова: навігаційна система, методи позиціонування та орієнтації, доповнена реальність.

\section{Вступ}

Сучасний стан розвитку мобільних пристроїв, зокрема технологія доповненої реальності(AR) за допомогою фреймворків ARCore [1] та ARKit [2] для платформ Android та iOS відповідно, дали змогу реалізувати ряд амбіційних ідей по створенню нових навігаційних систем. Серед нових можливостей, що надали описані фреймворки, можна виділити розпізнавання горизонтальних та вертикальних поверхонь, маркерне розпізнавання, точне обчислення результатів з акселерометра та гіроскопа, здатність синхронізації одного простору розпізнаних поверхонь на декілька пристроїв $[1,2,3]$. Завдяки цьому стає реальним створення алгоритмів для уточненого позиціонування на місцевості, що використовують як вхідні дані не лише GPS координати пристрою, а і його локальні зміщення, визначені акселерометром та гіроскопом. В свою чергу локальні зміщення можуть бути уточнені шляхом розпізнавання поверхонь об'єктів навколишнього середовища 3 вхідного відео потоку камери мобільного гаджета та аналізу їх змін в часі [3].

Такі алгоритми актуальні лише для так званих AR навігаторів, де візуалізація маршруту до точки проводиться у вигляді об'ємної полілінії, накладеної на зображення 3 камери. Дане твердження грунтується на тому, що звичайні навігатори з відображенням 2D карти не потребують значної точності (до 5-10 м), оскільки, навіть маючи високу точність позиціонування, не здатні інформативно це показати. В свою чергу, AR навігатори потребують високої точності позиціонування користувача в просторі, оскільки AR відображення маршруту має ідеально накладатись на реальний світ, відображений через камеру пристрою, інакше виведена інформація може бути незрозумілою.

(C) В.В. Олійник, Є.А. Яременко 


\section{Інформаційна модель AR навігатора}

На рис. 1 приведено загальну інформаційну модель AR навігатора [4].

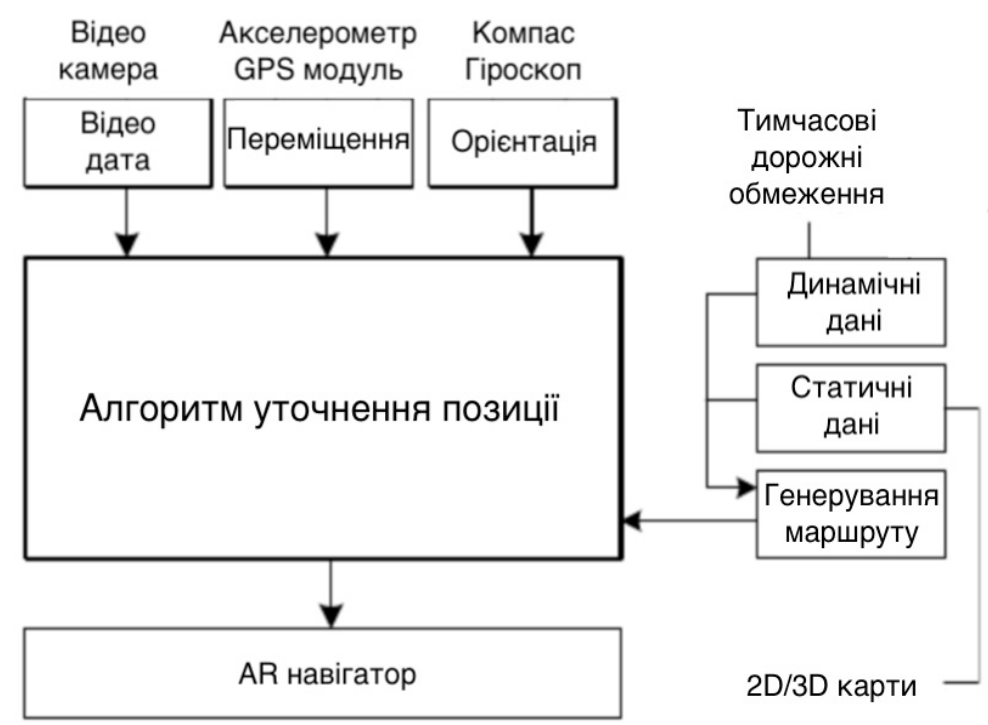

Puc. 1. Інформаційна модель AR навігатора

Для реалізації AR навігатора необхідно 2 види інформаційних потоків: дані про позиціонування та орієнтацію користувача та дані про місцевість.

В свою чергу перший інформаційний потік має включати 3 види інформації:

1. GPS координати та значення повороту пристрою за показаннями компаса, що дають грубе визначення позиції в глобальних координатах;

2. покази пристроїв про локальні переміщення (гіроскоп та акселерометр) для уточнення позиції з основних приладів позиціонування;

3. зображення з камери, необхідне для відображення навколишнього світу користувача, на яке буде накладатись інформація про маршрут.

Описані потоки даних являються вхідними даними для запропонованого нижче алгоритму уточненого позиціонування, який і лежить в основі AR навігатора.

Після визначення уточненої позиції та орієнтації в просторі необхідно розробити та відобразити маршрут до потрібного місця. Маршрут генерується у вигляді сукупності точок, де кожен вузол має координати і являє собою місце зміни напрямку. На маршрут впливають статичні (дороги, будівлі, ландшафт) i динамічні (ДТП, дорожні ремонти, затоплення зони) особливості місцевості.

Питання побудови та візуалізації маршруту на карті та екрані мобільного пристрою з урахуванням додаткових даних виходять за рамки даної статті, тому зазначимо лише, що для обробки даного потоку було використано зручний і багатофункціональний фреймворк Маpbox [5], реалізований у вигляді хмарного сервісу. 


\section{Аналіз існуючих підходів до уточнення позиціонування пристрою}

Найпоширенішим і найпростішим способом позиціонування є навігація виключно на основі GPS координат. Однак такий метод має найбільші похибки і не підходить для AR навігаторів. Для подолання похибок у відображенні AR маршруту на зображення реального світу можливі наступні підходи:

1. Уточнювати координати користувача за рахунок алгоритмів статистичного або імовірнісного аналізу серії неточних вимірювань 3 відомими імовірнісними характеристиками. Використовуючи у якості вхідних параметрів лише дані GPS-модуля, можна покращити результат на основі застосування так званих рекурсивних фільтрів або ймовірнісних методів обчислення.

Рекурсивні алгоритми уточнюють значення координат на основі послідовностей зашумлених вимірів у часі, тобто є фільтрами, які на основі зашумлених даних видають статистично оптимальне значення стану системи. Найбільш популярним фільтром в навігаційних системах є фільтр Калмана [6].

Ймовірнісні алгоритми мають схожий з рекурсивними фільтрами принцип роботи, що полягає в визначенні найбільш імовірного поточного стану системи (в випадку навігації - найбільш імовірна позиція користувача), виходячи 3 досліджень попередніх даних [7].

2. Використання альтернативних способів визначення положення, наприклад безпровідних технологій WiFi або BLE (Bluetooth Low Energy) точок. Суть методу [8] полягає у визначенні суперпозиції користувача за рахунок визначення його взаємного розташування відносно точок WiFi або BLE. Виходячи з практичних досліджень [9], метод позиціонування на основі WiFi/BLE точок показує значно нижчий результат, ніж використання рекурсивних фільтрів або ймовірнісних алгоритмів. Це зумовлено тим, що в містах, а тим більше поза їх межами відсутня однорідна мережа безкоштовних WiFi/BLE точок, а їх частотні характеристики сильно спотворюються. Тому дані методи застосовуються в місцях, де неможливе або ускладнення застосування систем глобальної навігації, наприклад, у будівлях.

3. 3 розвитком сенсорних систем, що вбудовуються в смартфони, виникають нові алгоритми позиціонування, які отримують на вході не тільки GPS координати, а і дані з інших інформаційних потоків (див. рис.1), зокрема, значення локальних зміщень пристрою - 3 акселерометра та гіроскопа. Використання декількох джерел даних замість одного дозволяє підвищити точність позиціонування, знижуючи потребу у великій кількості вимірювань та ймовірнісному або статистичному аналізі системи.

Звичайно, значення на виході акселерометра, магнітометра (компаса) та інших сенсорних приладів мобільного пристрою все одно обчислюються з похибкою [10]. Найпростіший спосіб зменшити похибку позиціонування - дозволити 
мануальне підлаштовування карти користувачу, тобто перетягнути і повернути утворену візуалізацію маршруту так, щоб вона стала на своє місце. Такий підхід застосовується, наприклад, в популярному додатку ARCity [11]. Більш перспективний спосіб корегування неточності приладів для визначення локальних переміщень полягає у застосуванні мобільних систем доповненої реальності, зокрема, ARKit або ARCore, які корегують вимірювання акселерометра та ін. за рахунок визначення горизонтальних та вертикальних поверхонь реального світу. Іншими словами, система здатна визначати зміщення пристрою за рахунок співставлення зображень у різні моменти часу [3]. При зростанні швидкості навігації розпізнавання зображень 3 камери має бути доповнено трекером об'єктів [12].

На практиці при застосуванні технологій доповненої реальності точність локального позиціонування значно зростає, що дозволяє нехтувати похибкою зміщень смартфона у локальній системі координат на невеликі відстані.

Очевидно, що саме останній підхід є найперспективнішим для реалізації в навігаційних системах доповненої реальності, оскільки без потреби ручного налаштування та великої кількості вимірювань потенційно може забезпечити не гірші результати за популярні методи нечіткої ідентифікації у просторі без додаткової інформації про характер нечіткості, імовірнісних характеристик неточних вимірювань тощо. До того ж, враховуючи новизну AR навігаторів, подібні алгоритми є недостатньо дослідженими. Тому, стаття присвячена актуальній проблемі реалізації методу мінімізації похибок позиціонування GPS модуля в типових мобільних пристроях на основі лише попередніх координат та показань вбудованих сенсорних пристроїв.

\section{Алгоритм уточнення положення на основі локальних зміщень пристрою}

Як було зазначено раніше, для реалізації алгоритму уточненого позиціонування на мобільних платформах доцільним є застосування технологій ARKit або ARCore, оскільки вони автоматично визначають кінцеве значення локальних зміщень девайсу (далі - сенсорні координати) і гарно інтегруються у навігаційні системи доповненої реальності.

Алгоритм роботи має циклічних характер. Кожен цикл розрахунків проводиться після оновлення даних GPS модуля.

Всі обчислення проводяться у локальній системі координат. Локальна система координат формується з дотриманням декількох правил:

1. масштаб системи координат по відношенню до світу - 1:1;

2. напрямки осей локальної системи координат співпадають зі сторонами світу, наприклад, північний напрямок - $(0,0,1)$, східний - $(1,0,0)$. 
3 цього випливає, що якщо пристрій користувача з початку сесії перемістився на 10 м на захід, його сенсорні координати мають бути $(-10,0,0)$.

Оскільки значення зміщень з гіроскопа та акселерометра визначаються без урахування правильної орієнтації на сторони світу, перед використанням їх повертають навколо центру координат на кут, рівний значенню кута компаса при старті алгоритму:

$$
L O C_{i+1}=L O C_{i}+T_{k} * \triangle L O C \#
$$

де $\triangle L O C, L O C$ - локальні зміщення мобільного пристрою, $T_{k}$ - матриця трансформації, яка повертає значення зміщення на необхідний кут компаса:

$$
T_{k}=\left(\begin{array}{ccc}
\cos (\alpha) & \sin (\alpha) & 0 \\
-\sin (\alpha) & \cos (\alpha) & 0 \\
0 & 0 & 1
\end{array}\right) \#
$$

Таким чином, локальна система координат відображає систему координат реального світу, однак їі центр знаходиться на початковому місці пристрою.

Оскільки GPS координати надходять у форматі широта-довгота, їх необхідно трансформувати у координати локальної системи. Одиниця виміру для обчислень - метр.

Для досягнення правильних значень локальних GPS даних, необхідно враховувати геометричні параметри Земної кулі в цілому та локальні висоти ландшафту. Для цього було використано можливості одного з найпоширеніших кросплатформених фреймворків Марbох [5].

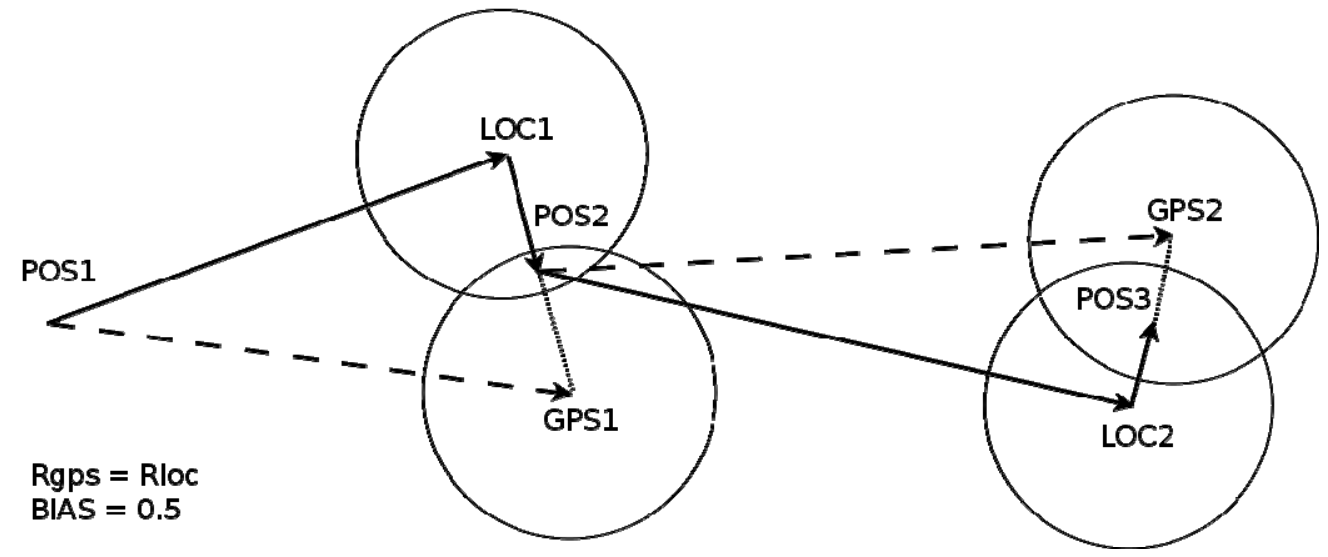

Puc. 2. Візуалізація описаного алгоритму уточненого позиціонування

Головною складністю алгоритму є те, що неточними є не тільки GPS дані, а і дані про локальні зміщення з гіроскопа та акселерометра. Ці локальні зміщення мають дуже високий ступінь точності лише на коротких відстанях. Саме тому алгоритм не проводить розрахунки один раз, а має циклічний характер і повторюється кожен раз при отриманні нових GPS даних. 
Виходячи $з$ попереднього твердження, задамо радіуси довіри для GPS координат та для локальних координат пристрою. Експериментальним шляхом визначено радіус довіри для локальних координат $R_{L O C}=10$ м. Для GPS координат доцільно використати аналогічний радіус $R_{\mathrm{GPS}}=10 \mathrm{M}$.

Також для гнучкого налагодження алгоритму перед початком його роботи обирається значення параметра $B I A S$, що характеризує розподіл довіри між даними від GPS модуля та від локальних зміщень. Так, якщо $B I A S=0$ значення локальних змін вважається істинним, і навпаки, якщо $B I A S=1$ істинним вважається значення GPS даних. Крім ручного задання параметру BIA дане значення може бути розраховано залежно від параметрів $R_{L O C}$ та $R_{\mathrm{GPS}}$ :

$$
B I A S=R_{L O C} /\left(R_{L O C}+R_{\mathrm{GPS}}\right) \#
$$

Опишемо один цикл розрахунку положення за алгоритмом (рис. 2):

1. На вхід циклу подається оновлене значення GPS координат користувача. Це значення трансформується в локальну систему координат $\mathrm{GPS}_{i+1}$ та записується в пам'ять.

2. На основі сенсорних координат з попереднього циклу та зміщень пристрою між поточним та попереднім циклами розраховується поточні сенсорні координати за формулою (1).

3. Маючи поточні значення локальних GPS та сенсорних координат, а також радіуси довіри по кожному з типів координат, за допомогою діаграми Венна визначається зона, в якій знаходиться істинна позиція користувача.

4. Для знаходження уточненої позиції користувача між $L O C_{i+1}$ та $\operatorname{GPS}_{i+1}$ відбувається лінійна інтерполяція з переметром BIAS:

$$
\mathrm{POS}_{i+1}=\mathrm{LOC}_{i+1}+\left(\mathrm{GPS}_{i+1}-\mathrm{LOC}_{i+1}\right) * \mathrm{BIAS \#}
$$

Ця позиція стає новою точкою відліку для майбутніх циклічних розрахунків.

5. Коли дані з GPS модуля оновлюються, алгоритм повторюється.

Для зменшення похибки орієнтації описаний метод модифікується таким чином, що після кожного циклу розрахунків локальна система координат повертається на кут $\beta$, рівний куту між векторами $\overrightarrow{\left(P O S_{l}, L O C_{l+1}\right)}$ та $\overrightarrow{\left(P O S_{l}, P O S i+1\right)}$ :

$$
T_{\text {loc }}=T_{\text {rot }} * T_{\text {loc }} \#
$$

де $T_{l o c}$ - матриця трансформації локальної системи координат, $T_{r o t}$ - матриця трансформації для повороту локальної системи координат на кут $\beta$ :

$$
T_{\text {rot }}=\left(\begin{array}{ccc}
\cos (\beta) & \sin (\beta) & 0 \\
-\sin (\beta) & \cos (\beta) & 0 \\
0 & 0 & 1
\end{array}\right) \#
$$




\section{Результати роботи алгоритму уточнення}

Для реалізації описаних алгоритмів було застосовано кроссплатформене середовище для розробки додатків Unity3D, плагіни ARKit та Mapbox. Для тестування та налагодження алгоритмів було створено симуляційний режим, що розраховував нову позицію користувача, приймаючи на вхід сукупність параметрів:

1. Точність GPS координат (в метрах);

2. Точність сенсорних даних з мобільного пристрою (у відсотках);

3. Точність компаса (у відсотках);

4. Параметр $B I A S$

На основі експериментальних досліджень вбудованих вимірювальних пристроїв смартфону iPhone 8 Plus при тестуванні алгоритмів було задано такі параметри:

1. Точність GPS - 20 м;

2. Точність гіроскопа для вимірювання повороту телефона - близька до $100 \%$;

3. Точність акселерометра для вимірювання локальних зміщень приймемо за 80\%. Причому вектор похибки завжди співпадає з вектором напрямку девайса;

4. Точність компаса - 95\%-99\%, оскільки в деяких випадках спостерігалось відхилення від правильного значення на $15^{\circ}$;

Дослідимо значення точності позиціонування за описаними алгоритмами (SIMPLE - без корекції кута повороту локальної системи координат; LERP - 3 корекцією) при зміні параметру BIAS Під час тестування алгоритмів маршрут був аналогічний в усіх випадках. Мінімальне значення пройденої відстані між двома сусідніми циклами обрахунків - 10м. В результатах експериментів відображено максимальне (MAX) та середнє (AVG) відхилення в метрах отриманого результату від еталонного.

Проаналізувавши результати (рис. 3) з більш реальною точністю компаса видно, що найкращим при заданих параметрах точності є алгоритм з корегуванням кута локальної системи координат використовуючи значення $B I A S \approx 0,5$. При зростанні точності компаса корисний ефект корегування кута зменшується і зникає.

Для більш наглядного аналізу алгоритму уточнення з корегуванням кута було отримано представлення двох траєкторій (рис.4.):

1. Темна траєкторія відображає позиції користувача, утворені лише $з$ даних GPS модуля. В даному випадку максимальне зміщення від еталонного положення - 20м, а середнє $-6,5 \mathrm{M}$.

2. Світла траєкторія відображає шлях, згенерований алгоритмом уточнення 3 корекцією кута локальної системи координат (LERP). В даному випадку максимальне відхилення позиції від бажаної - 15,2 м, а середнє $-4,4 \mathrm{M}$. 
Міжвідомчий науково-технічний збірник «Адаптивні системи автоматичного управління» № 2’ (33) 2018

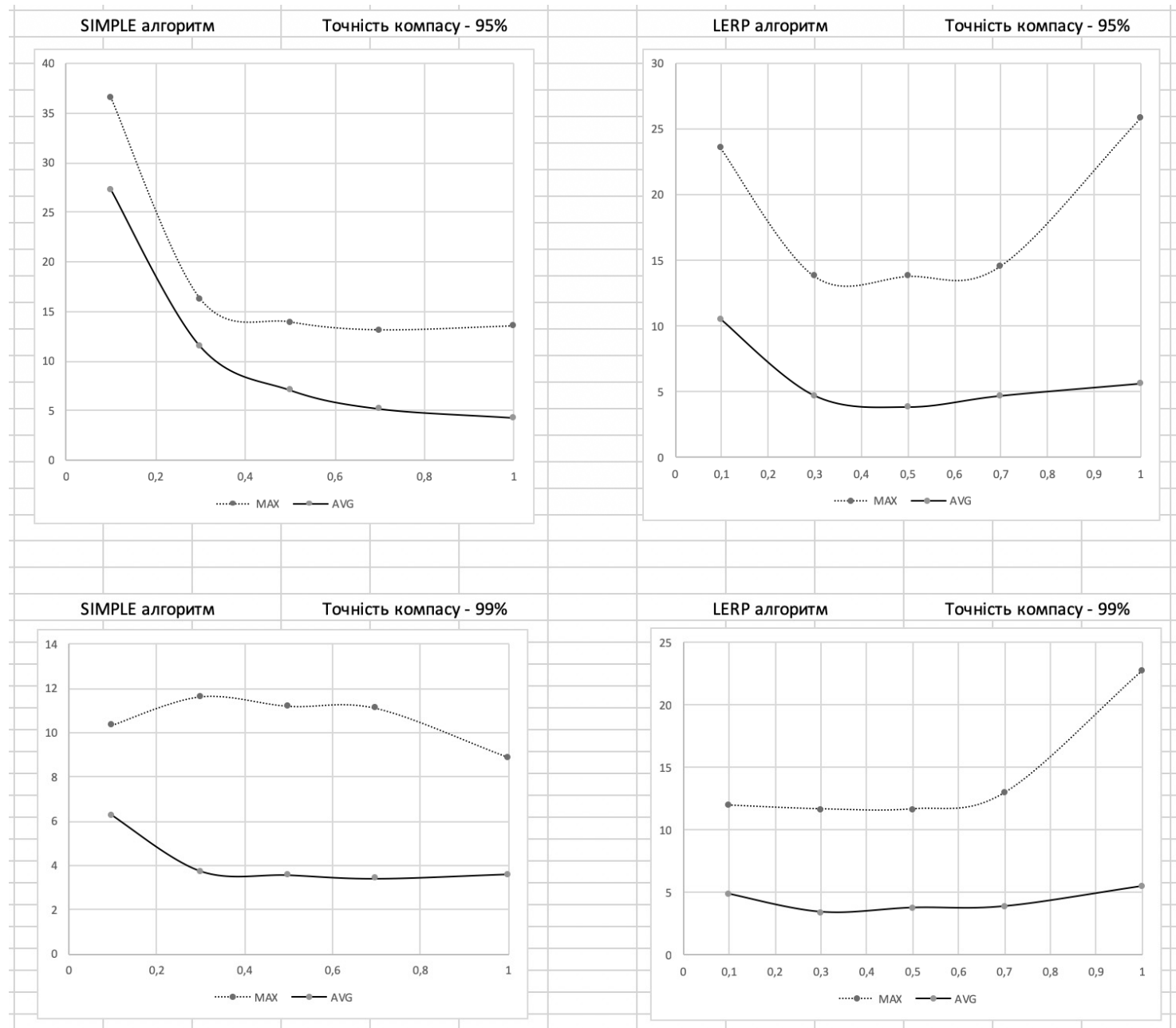

Puc. 3. Результати роботи алгоритмів уточнення при різних значеннях $B I A S$ та точності компаса

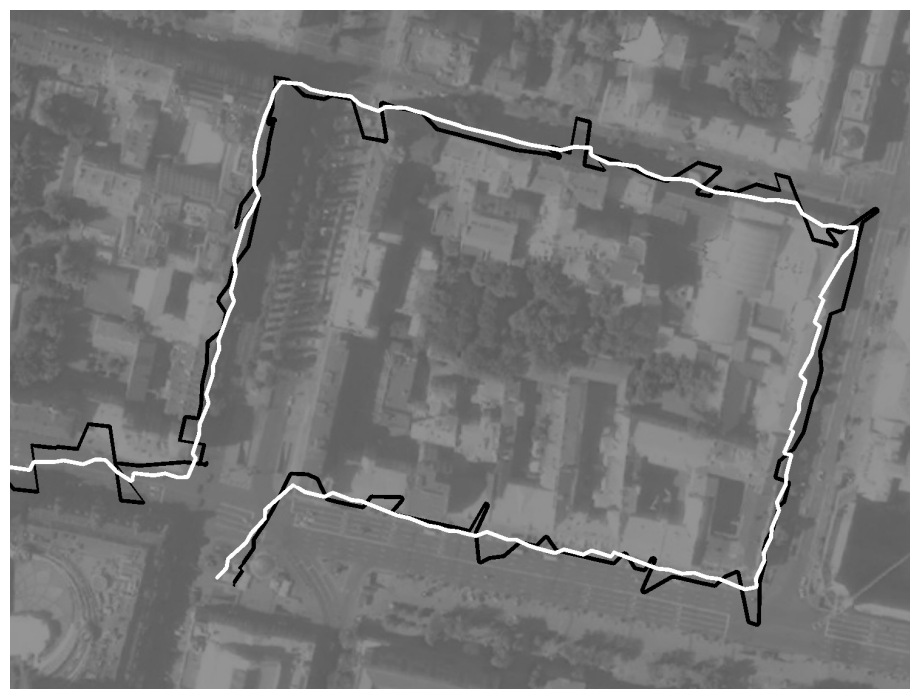

Puc. 4. Візуальне порівняння роботи алгоритмів: темна траєкторія - за GPS координатами, світла - алгоритм з уточненням 
SIMPLE алгоритм без корегування кута повороту локальної системи координат в даних умовах дає середнє відхилення від бажаної позиції 4,8 м.

В цілому ж результати дослідження роботи запропонованого алгоритму демонструють значне покращення точності позиціонування порівняно з використанням лише GPS координат - понад 30\%.

Також дослідження показали, що на результат роботи алгоритму сильний вплив має похибка компаса, яка за певних умов може суттєво перевищувати прийняту в дослідженні [10]. Проблему можна вирішити розробкою методів валідації показаннями з інших джерел або введенням калібраційного режиму, при якому під час старту навігації користувач може сам відкоригувати поворот карти відносно сторін світу. До того ж це може бути зроблено просто і наочно з використанням можливостей доповненої реальності.

\section{Висновки}

Запропонований алгоритм геометричного визначення позиції користувача на основі даних GPS-модуля та локальних зміщень мобільного пристрою може бути ефективно застосований в навігаційних системах доповненої реальності, особливо при використанні візуального розпізнавання поверхонь реального світу, що значно підвищує точність локального позиціонування пристрою.

Результати експериментальних досліджень свідчать, що при заданих реальних похибках вимірювань сенсорних пристроїв алгоритм демонструє точність на понад 30\% вищу за базовий метод на основі лише GPS координат.

Перспективно виглядає розробка модифікацій даного алгоритму з урахуванням наявної інформації про імовірнісні характеристики нечітких вимірювань наявних приладів. Також, окремим питанням подальших досліджень є підвищення ефективності використання відео даних - розпізнавання оточуючих поверхонь, їх положення, віддаленості та орієнтації і врахування цих даних при розрахунку локальних переміщень та глобального положення.

\section{Список використаних джерел}

1. ARCore [Електронний ресурс] // ARCore. 2018. URL: https://developers.google. com/ar/.

2. Dilek U., Erol M. Detecting position using ARKit // Physics Education. 2018. T. 53. №. 2.

3. Rettenmund D. Accurate visual localization in outdoor and indoor environment exploiting 3D image spaces as spatial reference // International Archives of the Photogrammetry, Remote Sensing \& Spatial Information Sciences. 2018. T. 42. №. 1.

4. Narzt W., Pomberger G., Ferscha A. Augmented reality navigation systems // Universal Access in the Information Society. 2006. C. 177-187. 
5. How Mapbox work [Електронний ресурс] // Mapbox. 2018. URL: https://www.mapbox.com/help/how-mapbox-works/.

6. Robert M. Leishman C. Multiplicative Extended Kalman Filter for Relative Rotorcraft Navigation // Journal of Aerospace Information Systems. 2014. C. 728- 744

7. Madigan D. Bayesian indoor positioning systems //24th Annual Joint Conference of the IEEE Computer and Communications Societies. Proceedings IEEE. 2005. C. 1217-1227.

8. Cong Chao, An Innovative Indoor Location Algorithm Based on Supervised Learning and WIFI Fingerprint Classification // International Conference On Signal And Information Processing, Networking And Computers. 2017. C. 238-246.

9. Аверин И.М. Позиционирование пользователей с использованием инфраструктуры локальных беспроводных сетей // IV Всероссийская конференция «Радиолокация и радиосвязь». 2010.

10. Neumeier R., Ostermayer G. Analysis of compass sensor accuracy on several mobile devices in an industrial environment // International Conference on Computer Aided Systems Theory. Springer, Berlin, Heidelberg, 2013. C. 381-389.

11. Welcome to AR City [Електронний pecypc] // Blippar. 2018. URL: https://www.blippar.com/blog/2017/11/06/welcome-ar-city-future-maps-and-navigation.

Пантелеев А.С., Олейник В.В. Метод визуального мультитрекинга в реальном времени на основе корреляционных фильтров // Міжвідомчий науково-технічний збірник "Адаптивні системи Автоматичного Управління", К: Політехніка. 2018. Т.1, №32. C. 97-106. 